\title{
A Variable Trajectory Model for Regional Assessments of Air Pollution From Sulfur Compounds
}

D. C. Powell

D. J. McNaughton

L. L. Wendell

R. L. Drake

February 1979

Prepared for the U.S. Department of Energy under Contract EY-76-C-06-1830

Pacific Northwest Laboratory Operated for the U.S. Department of Energy by Battelle Memorial Institute 


\title{
NOTICE
}

This report was prepared as an account of work sponsored by the United States Government. Neither the United States nor the Department of Energy, nor any of their employees, nor any of their contractors, subcontractors, or thei: employees, makes any warranty, express or implied, of assumes any legal liabilicy or responsibility for the accuracy, completeness or usefulness of any information, apparatus, product or process disclosed, or represents that its use would not infringe privately owned rights.

The views, opinions and conclusions contained in this report are those of the contractor and do not necessarily represent those of the United States Government or the United States Department of Energy.

\author{
PACIFIC NORTHWEST LABORATORY \\ operated by \\ BATTELLE \\ for the \\ UNITED STATES DEPARTMENT OF ENERGY \\ Under Contract EY-76-C-06-1830
}

\begin{tabular}{|c|c|}
\hline \multirow{2}{*}{\multicolumn{2}{|c|}{$\begin{array}{l}\text { Printed in the United States of America } \\
\text { Available from } \\
\text { Nationai Tec hnical Information Service } \\
\text { United States Department of Commerce } \\
\text { 5285 Port Royal Road } \\
\text { Springfield, Virginia } 22157 \\
\text { A. Printed Coous - Mirntiche } 53\end{array}$}} \\
\hline & \\
\hline -Pages & $\begin{array}{c}\text { NTIS } \\
\text { Selling Price }\end{array}$ \\
\hline $001-125$ & $\$ 4.00$ \\
\hline $026-050$ & $\$ 4.50$ \\
\hline $057-075$ & $\$ 5.25$ \\
\hline $076-100$ & 36.00 \\
\hline $101-125$ & $\$ 6.50$ \\
\hline $126-150$ & 37.25 \\
\hline $757-175$ & 58.00 \\
\hline $176-200$ & $\$ 9.00$ \\
\hline $207-225$ & $\$ 9.25$ \\
\hline $22 t-250$ & $\$ 9.50$ \\
\hline $251 \cdot 275$ & 510.75 \\
\hline $276-300$ & 511.00 \\
\hline
\end{tabular}


PNL -2734

33679000491755

UC-11

A VARIABLE TRAJECTORY MODEL FOR REGIONAL ASSESSMENTS OF AIR

POLLUTION FROM SULFUR COMPOUNDS

D. C. Powe 11

D. J. McNaughton

L. L. Wende 11

R. L. Drake

February 1979

Prepared for

the U.S. Department of Energy

under Contract EY-76-C-06-1830

Pacific Northwest Laboratory

Richland, Washington 99352 
* 


\section{SUMMARY}

This report describes a sulfur oxides atmospheric pollution model that calculates trajectories using single-layer historical wind data as well as chemical transformation and deposition following discrete contaminant air masses. Vertical diffusion under constraints is calculated, but all horizontal dispersion is a function of trajectory variation. The ground-level air concentrations and deposition are calculated in a rectangular area comprising the northeastern United States and southeastern Canada.

Calculations for a 29-day assessment period in April 1974 are presented along with a limited verification. Results for the studies were calculated using a source inventory comprising $61 \%$ of the anthropogenic $\mathrm{SO}_{2}$ emissions. Using current model parameterization levels, predicted concentration values are most sensitive to variations in dry deposition of $\mathrm{SO}_{2}$, wet deposition of sulfate, and transformation of $\mathrm{SO}_{2}$ to sulfate. Replacing the variable mixed-layer depth and variable stability features of the model with constant definitions of each results in increased ground-level concentration predictions for $\mathrm{SO}_{2}$ and particularly for sulfate. 
CONTENTS

SUMMARY

FIGURES

vi i

TABLES

INTRODUCTION

CONCLUSIONS

MODEL DESCRIPTION

CALCULATION GRIDS

TRANSPORT CALCULATIONS

DIFFUSION AND DIFFUSION CONSTRAINTS

TRANSFORMATION AND REMOVAL MECHANISMS

CONTRIBUTION OF $\mathrm{H}_{2} \mathrm{SO}_{4}$ DISSOCIATION TO RAINFALL ACIDITY

MODEL RESULTS

TEST SIMULATION DATA

Wind Data

Precipitation Data

Emissions Data

Observations for Model Testing

TEST-CASE RESULTS

SENSITIVITY ANALYSIS RESULTS 


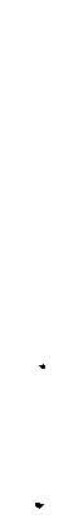




\section{FIGURES}

1 Wind Station Distribution with Reference to the Advection Grid (Inner Rectangle) and a Portion of NMC

Octagonal Northern Hemisphere Grid . . . . . . . . 6

2 Daytime Illustration of Stability Definition and Vertical Constraints . . . . . . . . . . . 12

3 U.S. Precipitation Station Distribution and Sampling Grid . . 20

4 Source Distribution: Utility, Nonutility . . . . $\quad 22$

5 Predicted Average Ground-Level Concentrations

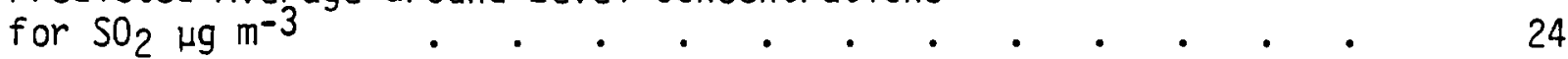

6 Predicted Average Deposition Rate for $\mathrm{SO}_{2}, \mu \mathrm{g} \mathrm{m}-2 \mathrm{yr}^{-1}$. . . . . . . . . . .

7 Predicted Average Ground-Level Air Concentrations

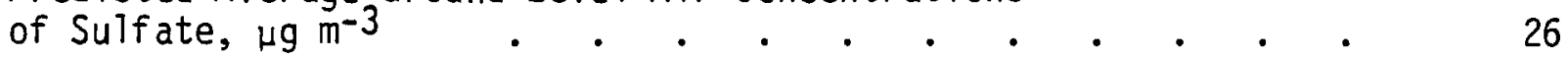

8 Predicted Average Deposition Rate for Sulfate, $\mu \mathrm{g} \mathrm{m} \mathrm{m}^{-2} \mathrm{yr}^{-1}$

9 Observed Average Ground-Leve 7 Concentrations of Sulfate, $\mu \mathrm{g} \mathrm{m}^{-3}$. . . . . . . . . . . . . 30

10 Predicted Average pH of Rainfall . . . . . . . . . 31

\section{TABLES}

1 Mass Batance Summary . . . . . . . . . . .

2 Average Values of Vertical Distribution Factor $\left(z^{-1}\right) \quad$. . . 34

3 Sensitivity Test Results . . . . . . . . . . 


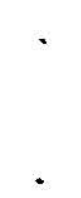




\section{INTRODUCTION}

Because of potential health and ecological effects of air contaminants, (1) the U.S. Department of Energy (DOE) and the Electric Power Research Institute (EPRI) are currently sponsoring programs to assess, on a multistate scale, the impact of sulfur oxide emissions from fossil-fuel-fired generating plants and other industrial emission sources. $(2,3)$

This document presents a regional-scale, assessment model designed for economical computation of long-term averages of ground-level air concentration and deposition rate of sulfur dioxide $\left(\mathrm{SO}_{2}\right)$ and of sulfate $\left(\mathrm{SO}_{4}^{\overline{ }}\right)$. The term "regional" embraces horizontal scales of 25 to $2500 \mathrm{~km}$; (4) the final recommended averaging time is 1 mo or more. The model also uses hourly real-time precipitation and estimates rainfall pH, averaged over the total assessment period.

This discussion provides a complete model description, including model formulation and test case and sensitivity studies. Section 2 discusses model description. Test-case input data, test-case results and sensitivity analysis results follow in Section 3 .

The test case includes 29-day averages computed over a 1360 by $2040 \mathrm{~km}$ grid over the northeastern United States, using an inventory of 60 sources and stepping in 1-hr increments. Thus used, the model achieves an 11,000 to 1 ratio of real time to running time on the $\operatorname{CDC} 7600$ computer. 

CONCLUSIONS

A model test case was evaluated and model results were compared to observed ground-level air concentration data for sulfate at 107 stations throughout the northeastern United States. Using these data for regression of predicted results against observed results, a correlation of 0.43 was obtained. Furthermore, using an emissions inventory believed to account for approximately $61 \%$ of the $\mathrm{SO}_{2}$ emissions in the predicted sulfate concentration accounts for an average of $53 \%$ of the corresponding observed results. Nonrepresentative observational data used to describe regional pollutant behavior are believed to contribute to this relatively low correlation value. However, substantial improvements can be made in the model by more sophisticated parameterization of removal and transformation, including the appropriate variation of these parameters with physical conditions.

Sensitivity estimates made directly from the numerically specified equations for removal and transformation of mass indicate: if parameter levels for each of these processes are varied within the same ratio limits of presently assumed values, the ground-level concentrations are more sensitive to dry deposition of $\mathrm{SO}_{2}$, wet deposition of sulfate, and transformation than to wet deposition of $\mathrm{SO}_{2}$ and dry deposition of sulfate. Sensitivity tests also indicate that with this model, constant stability increased both predicted levels of $\mathrm{SO}_{2}$ ground-leve 1 air concentrations and deposition by $22 \%$, while the predicted sulfate ground-level air concentration increased $73 \%$.

The ratio of real time to execution time for the 60-source inventory, 29-day run described is greater than 11,000 to 1 on the CDC 7600 computer. The required execution time was 219 seconds. 



\section{MODEL DESCRIPTION}

\section{CALCULATION GRIDS}

Model calculations are performed on a rectangular grid, which is a subset of the National Meteorological Center (NMC) Northern Hemisphere grid. The area for calculation in the test case, presented in the following section (see Figure 1), covers the northeastern United States and a portion of southern Canada. It extends $2040 \mathrm{~km}$ on the abscissa and $1360 \mathrm{~km}$ on the ordinate.

Two grids are defined on this area. The advection grid (see Figure 1) is formed by dividing the area into a 12 by 8 array of squares so that each square is $1 / 2$ NMC grid unit long, with an average linear dimension of $170 \mathrm{~km}$. Because of the polar stereographic projection of the NMC grid, the actual grid-square dimensions are a function of latitude; the dimensions of the advection grid unit $\left(\Delta G_{a}\right)$ are:

$$
\Delta G_{a}=190.5 \frac{1+\sin \phi}{1+\sin (\pi / 3)} \mathrm{km}
$$

where $\phi$ is the latitude in radians.

The second or sampling grid has elements with linear dimensions $1 / 5$ the advection grid spacing. Therefore, the sampling grid divides the predictive area into an array of 60 by 40 squares.

\section{TRANSPORT CALCULATIONS}

Trajectories are simulated for plume elements released hourly from several emission source locations. Emission rate at the source position determines the initial sulfur dioxide mass of each plume element. The initial sulfate mass is zero. Subsequent horizontal transport of these plume elements is in hourly steps using the layer-averaged winds at each advection-grid, intersection point. An objective analys is scheme developed for mesoscale purposes $^{(5)}$ interpolates wind data in space and time to provide the hourly winds at each particle position. The current transport scheme has no vertical component. It is assumed that the concentrations of sulfur oxides are averaged over a time period in which the effects of vertical atmospheric 


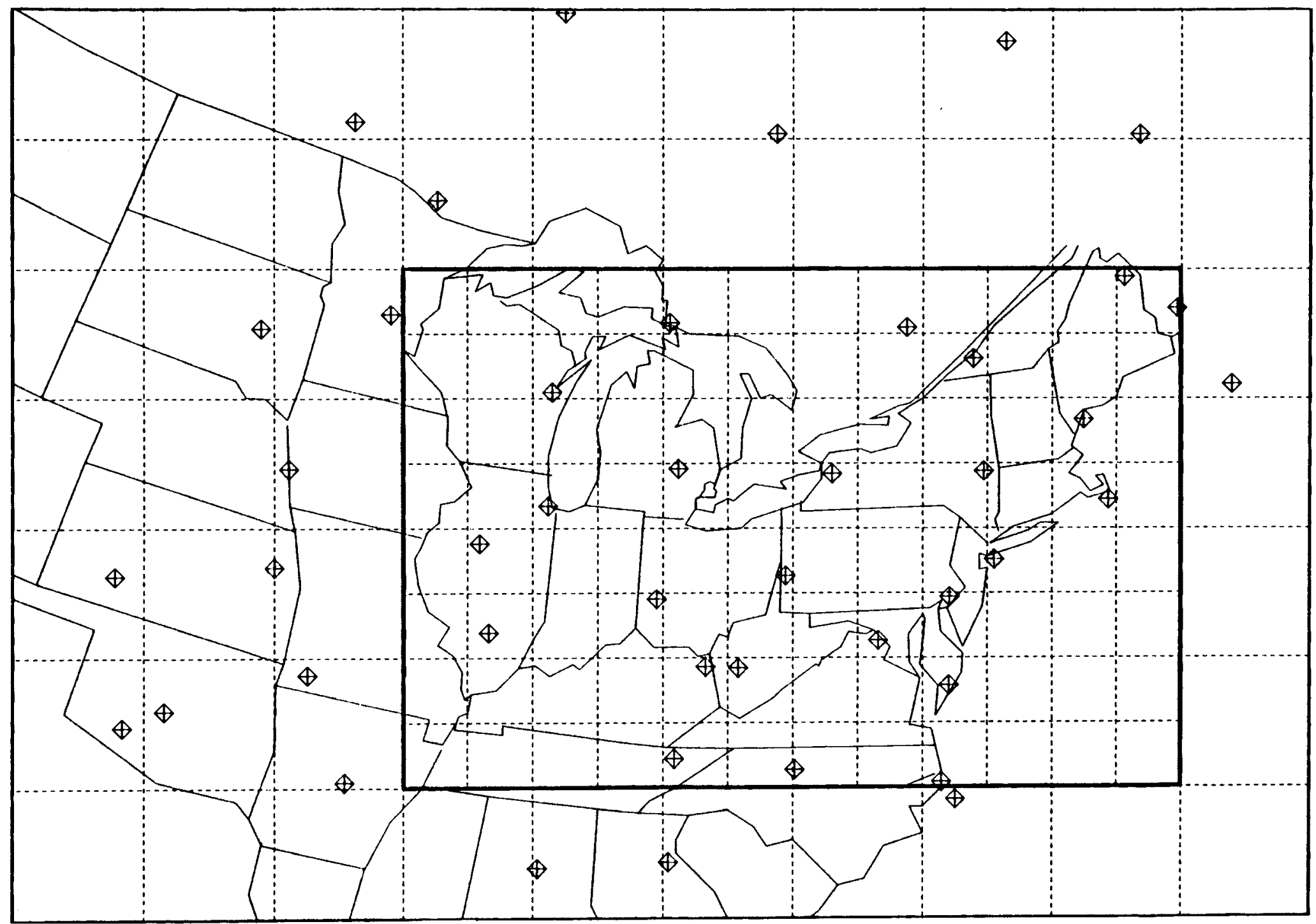

FIGURE 1. Wind Station Distribution with Reference to the Advection Grid (Inner Rectangle) and a Portion of NMC Octagonal Northern Hemisphere Grid 
processes can be adequately expressed by the parameterized vertical component of diffusion and by the mixing depth constraints. It is also assumed that the effects of vertical transport on horizontal transport can be neglected over the long assessment time period.

\section{DIFFUSION AND DIFFUSION CONSTRAINTS}

The following assumptions are made on atmospheric diffusion:

1. Horizontal diffusion is a function of synoptic scale wind variation on ly. Tennekes, (6) Bolin and Persson, (7) and Prahm and Christensen ${ }^{(8)}$ support this assumption. All state that either horizontal turbulent diffusion about the plume center line is relatively unimportant or that it is less important than plume meandering.

2. The vertical-turbulent diffusion parameterization is a function of stability in a specified diurnal cycle for all plume elements within the daytime mixed layer or the nocturnal stable layer.

3. The depth of the daytime mixed layer is represented by a diurnal cycle in which a daytime layer increases from a minimum depth at sunrise to a maximum depth in the afternoon. A nocturnal layer builds to a lower depth.

4. Depth of the boundary layer (mixed layer in daytime or nocturnal layer) for each hour determines which of two vertical dispersion regimes - mixed layer or above mixed layer - will be applied to a given plume element. Those elements released within the depth of the layer expand according to the stability of the hour. Those released above the current depth of the layer expand as if the atmosphere were extremely stable. An exception to this method occurs when releases have expanded to the maximum depth of the mixed layer during the previous day; in this case, their expansion continues according to a fixed function of travel time independent of stability or layer depth.

5. Depth of the mixed layer provides a vertical constraint for releases at heights within this layer. The depth of the nocturnal boundary does not serve as an analogous constraint. Carson ${ }^{(9)}$ supports this assumption 
by depicting the mixed-layer depth as a function that increases during the daytime, then loses its definition. This picture is in relative agreement with modeling results by Venkatram and Viskanta ${ }^{(10)}$ and with experiment results by Kaimal et al., (11) who find that about $1 \mathrm{hr}$ before sunset the convective layer disintegrates rather abruptly, al though remnants of the capping inversion persist through the development of the nocturnal boundary layer.

6. At the present stage of model development, terrain effects are neglected. Diffusion equations are best explained by relating them to final concentration and deposition calculations where the average ground-level air concentrations of pollutant $(n)$ over grid square $(i, j)$ are given by summing time-integrated concentrations [integrated over time interval $(\Delta t)$ ] and dividing by total assessment time $(T)$. Thus,

$$
x_{n}^{i j}=T^{-1} \sum_{m(t)} \Delta x_{m n}^{i j}(\Delta t ; t) .
$$

where $\Delta x_{m n}^{i j}$ is the time-integrated ground-level air concentration over $(i, j)$ for pollutant $(n)$ carried by each plume element $(m)$ that is located over $(i, j)$ at time $(t)$.

$\Delta x_{m n}^{i j}$ is computed at the end of each sampling interval $(\Delta t)$ for each pollutant constituent of each plume element that is on the grid by

where

$$
\Delta x_{m n}^{i j}(\Delta t ; t)=\frac{Q_{m n}(t) \Delta t}{A^{i j} Z_{m}},
$$

- $Q_{m n}(t)$ is the mass of $n$ carried by $m$ at $t$

- $A^{i j}$ is the area of $(i, j)$

- $Z_{\mathrm{m}}$ is the vertical distribution factor for $m$ calculated by assuming Gaussian vertical distribution modified by reflection from the ground and from the top of the mixed layer. 
If the vertical constraint height is $L$ and the effective stack height is $H, Z_{m}^{-1}$ is:

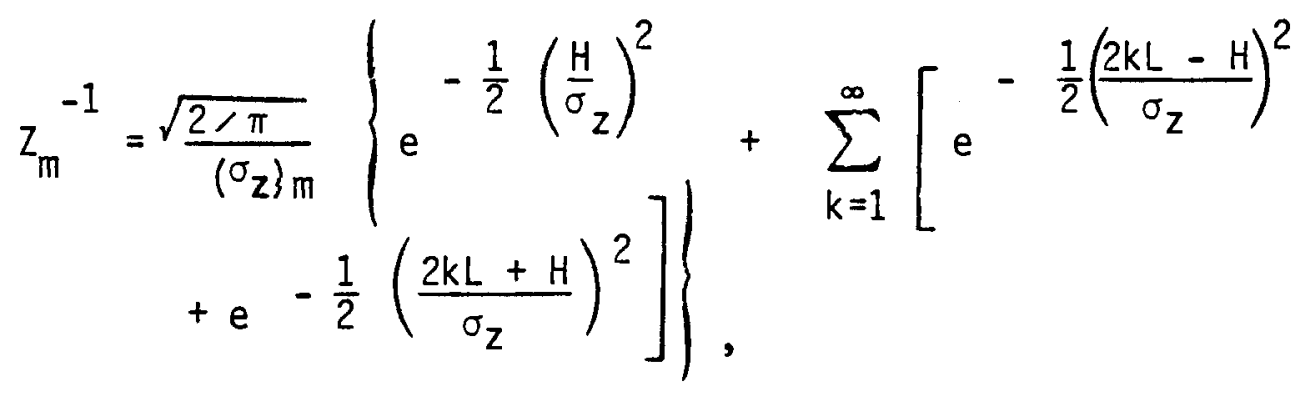

where $\left(\sigma_{z}\right)_{m}$ is the vertical standard deviation for plume element $m$.

If $\sigma_{z}$ is small compared to $L$, the term represented by the entire summation over $k$ may be neglected. If $\sigma_{z}$ is approximately equal to or larger than $L$, the vertical distribution is approaching uniformity. Therefore, instead of calculating $Z^{-1}$ by a wastefur summation, $Z$ is set equal to $L$ :

$$
Z=L
$$

$L$ is the height of a reflection effective for transport at height $H$.

In the model, the depth in meters of the daytime mixed layer $\left(L_{d}\right)$ is given by:

$$
L_{d}\left(t_{h}\right)=200+1300 \sin \left[0.05 \pi\left(t_{h}-6\right]\right.
$$

when

$$
6 \leq t_{h} \leq 18
$$

and the depth of the nocturnal boundary layer $\left(B_{n}\right)$ is given by:

$$
B_{n}\left(t_{h}\right)=100+300 \sin \left[0.05 \pi\left(\left(t_{h}-18\right)\right)\right]
$$

when

$$
18<t_{h}<30
$$


where $t_{h}$ is the hour of the day un less $t_{h}$ is greater than 24, in which case $t_{h}$ is specified as the hour of the day plus 24 to provide a continuous function.

These formulae were drawn up to approximate graphic results given by Carson. (9) They are advanced only for purposes of the calculations of this model, because the typical daytime mixed layer increases from $200 \mathrm{~m}$ at sunrise to $1500 \mathrm{~m}$ by late afternoon, and a nocturnal boundary layer develops to about $400 \mathrm{~m}$.

A11 plume elements not spread beyond the mixed-layer depth ( $L$ ) expand vertically as a function of travel distance. The increase of $\sigma_{z}$ is calculated using

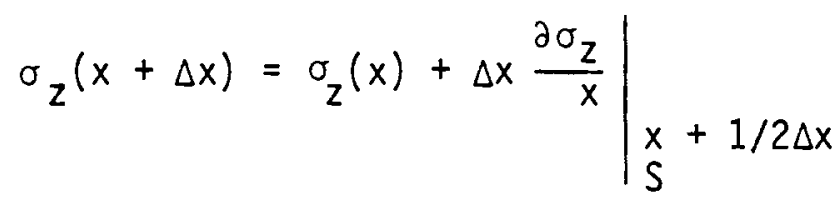

where $S$ indicates the derivative differs according to the stability that is hourly specified in the model.

The formulae thus differentiated are those of Eimutis and Konicek (12) If $H$ is greater than the mixed-layer depth $\left(L_{d}\right.$ or $\left.B_{n}\right)$, whichever applies at the time, the plume elements expand at the rate of $60 \%$ of that for Pasquill Stability 6. (a) This expansion rate results because mixing by mechanical turbulence is not effective above the mixed layer; therefore, the rate of vertical expansion is minimal.

All plume elements, which have expanded vertically to fill the mixed layer at its maximum depth, are released from the mixed-layer constraint at

(a) D. C. Powe11, H. L. Wegley and T. D. Fox MESODIF-II: A variable trajectory plume segment model to assess ground-level air concentrations and deposition of routine effluent releases from nuclear power facilities. To be published by the U.S. Nuclear Regulatory Commission. 
sunset when the boundary-layer structure collapses. These puffs expand as a function of time according to

$$
\sigma_{z}\left(t+\Delta t ; L_{d m}\right)=\sigma_{z}\left(t ; L_{d m}\right)+\Delta t \sqrt{K_{z} / 2 t}
$$

where $K_{z}$ is the vertical diffusivity.

Heffter and Ferber ${ }^{(13)}$ recommend a value of $5 \mathrm{~m}^{2} \mathrm{~s}^{-1}$ for $\mathrm{K}_{z}$. The plume elements not subject to the mixed-layer constraint after sunset include almost all those emitted during the previous $24 \mathrm{hr}$. Since these plumes all have the same vertical distribution at sunset, taken to be 1800 , they are all assigned a common value of $t, 12 \mathrm{hr}$. If $L_{d m}$ is the maximum depth of the mixed layer at $t_{h}=18$ for each of these plume elements, then

$$
\sigma_{z}\left(12 \mathrm{hr} ; L_{d m}\right)=\left.\sigma_{z}\right|_{t_{h}=18}=\frac{L_{d m}}{\sqrt{\pi / 2}} .
$$

A Gaussian plume calculation with $\sigma_{z}=L_{d m} \sqrt{2 / \pi}$ yields the same ground concentration as calculations for evenly distributed plumes over a layer of depth $L_{d m}$. Further plume expansion in time interval $(\Delta t)$ is given by

$$
\sigma_{z}(12+\Delta t)=\frac{L_{d m}}{\sqrt{\pi / 2}}+\Delta t \sqrt{\frac{K_{z}}{2(12+\Delta t)}} .
$$

The daytime plume expansion is illustrated in Figure 2. The plume at the bottom left is a low-level release, which expands at a rate corresponding to the stability of the hour to a height not greater than that of the mixed-layer depth. Farther to the right, an elevated plume is released above the mixed layer. It expands very slowly so that it does not contribute to surface concentrations. Above both plumes, the depth of the boundary-layer is shown by $L_{d}$. At a later hour when $L_{d}$ rises above the stack, the second plume will also expand according to the stability of the hour. Above $L_{d m}, \sigma_{z}$ of a 


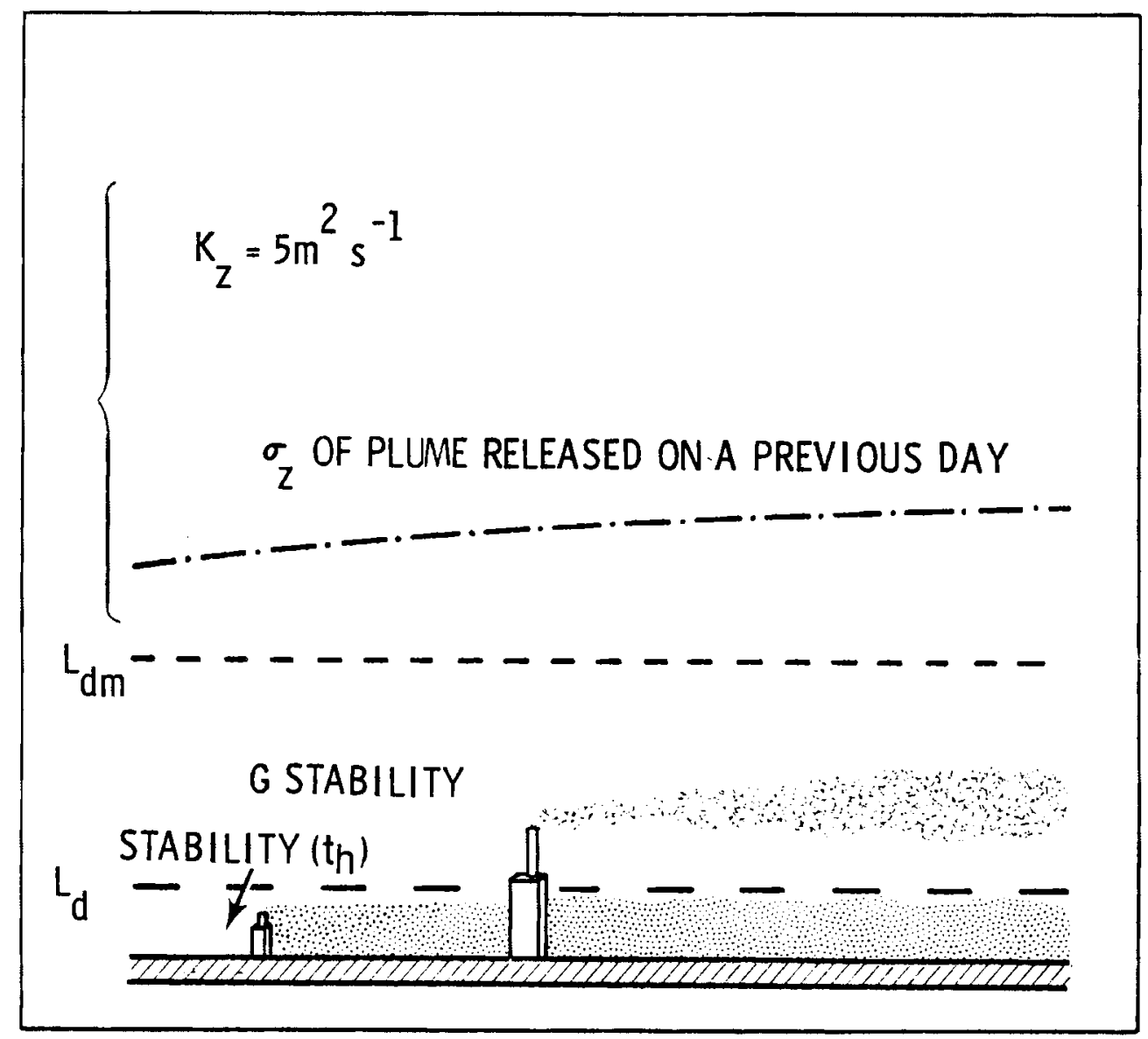

FIGURE 2. Daytime Illustration of Stability Definition and Vertical Constraints.

plume released on a previous day is shown. It expands at the rate given by Equation (9). This expansion rate reflects the effects of convection averaged over a 24-hr period at the higher levels.

The hourly stability array used for the diurnal cycle generally allows for stable conditions at night, unstable conditions in the afternoon and neutral transition hours. The portion of time allotted to each classification corresponds to the climatology of stability for the spring season over the northeastern United States discussed by Doty, Wallace and Holzworth. (14) During unstable hours in the afternoon, all plume elements quickly become even ly distributed throughout the mixed layer. 
TRANSFORMATION AND REMOVAL MECHANISMS

The transformation of $\mathrm{SO}_{2}$ to sulfate and the removal of $\mathrm{SO}_{2}$ and sulfate from the atmosphere by dry and wet deposition are calculated by a set of ordinary linear differential equations that are solved for each plume element. These equations assume that:

- transformation is a linear, first-order process.

- Dry-removal rate is obtained by multiplying the deposition velocity by the vertical distribution factor $z^{-1}$.

- Wet-removal rate is directly proportional to the local precipitation rate. The following definitions are used in the equations:

$Q_{1}(t), Q_{2}(t)=$ masses of $\mathrm{SO}_{2}$ and sulfate in a plume element at time, $t, \mu g$

$D_{1}(t), D_{2}(t)=$ masses of $\mathrm{SO}_{2}$ and sulfate deposited from a plume e lement up to time, $t, \mu g$

$d_{1} d_{2}=$ coefficients of dry deposition of $\mathrm{SO}_{2}$ and sulfate, $\mathrm{hr}^{-1}$

$\mathrm{w}_{1}, \mathrm{w}_{2}=$ coefficients of wet deposition of $\mathrm{SO}_{2}$ and sulfate, $\mathrm{hr}^{-1}$

$r_{12}$ $=$ transformation rate of $\mathrm{SO}_{2}$ to sulfate, $\mathrm{hr}^{-1}$

In this notation $Q_{1}(t)$ is equivalent to $Q_{m 1}(t)$ in Equation (3). For the sake of simplicity, the $m$ notation is suppressed.

Given the above definitions,

$$
\begin{aligned}
& \frac{d Q_{1}}{d t}=-\left(d_{1}+w_{1}+r_{12}\right) Q_{1}, \\
& \frac{d Q_{2}}{d t}=-\left(d_{2}+w_{2}\right) Q_{2}+1.5 r_{12} Q_{1}, \\
& \frac{d D_{1}}{d t}=\left(d_{1}+w_{1}\right) Q_{1}, \\
& \frac{d D_{2}}{d t}=\left(d_{2}+w_{2}\right) Q_{2} .
\end{aligned}
$$


The 1.5 factor in Equation (12) accounts for different masses associated with equimolar quantities of sulfate and $\mathrm{SO}_{2}$. Solutions of these equations are expressed by the change of mass for each plume element $(m)$ over the advection time $(\Delta t)$ and by the mass to be deposited over grid unit $(i, j)$ from $m$ over the same time interval, usually $1 \mathrm{hr}$.

The calculated deposition is expressed in terms of mass $\mathrm{m}^{-2} \mathrm{yr}^{-1}$. Thus, the annual deposition $(F)$ of pollutant $(n)$ applying to $i, j$ may be written as:

$$
F_{n}^{i j}=Y^{-1} T^{-1} \sum_{m(t)} \Delta F_{m n}^{i j}(\Delta t ; t)=Y^{-1} T^{-1} \sum_{m(t)} \frac{D_{m n}^{i j}(\Delta t ; t)}{A^{i j}}
$$

where $Y$ is $1 \mathrm{yr}$ in units of $T$ and $\Delta F_{m n}^{i j}$ is the deposition of pollutant $n$, mass per unit area, over $t$ ime interval $(\Delta t)$ over grid square $i, j$ because of plume element $m$ at time $(t)$.

In $D_{m n}^{i j}(\Delta t ; t), n=1,2$ is a more complete notation for the deposited mass. The $D_{m n}^{i j}$ are divided into dry and wet deposition:

$$
D_{m n}^{i j}=Q_{m n} D_{m n}^{i j}(\Delta t ; t),
$$

where $D_{m n}^{i j}(\Delta t ; t)$ is given by:

$$
D_{m n}^{i j}(\Delta t ; t)=1-\operatorname{EXP}\left\{\left[-\frac{\overline{v_{n}}}{z_{m}(t)}-\lambda_{n} p^{i j}(t)\right] \Delta t\right\} .
$$

where

- $\overline{V d_{n}}$ is the deposition velocity for $n$.

- $z_{m}(t)$ is the vertical distribution factor for $m$.

- $p^{i j}(t)$ is the precipitation rate at $t$ over $i, j$.

- $\lambda_{n}$ is an inverse length scavenging parameter for $n$. 
The mode 1 currently assumes that $V d_{n}$ and $\lambda_{n}$ are constants.

Relating Equations (14) and (15) to Equation (18) yields

$$
\begin{aligned}
& d_{n}=\overline{V d_{n}} / Z_{m}(t), \\
& w_{n}=\lambda_{n} p^{i j}(t) .
\end{aligned}
$$

A constant value for each of these parameters was selected even though they are all known to vary in space and time with changing physical conditions. The object is to establish a performance level for the model by comparing predicted results with observed results as a base case for sensitivity studies (see page 28 of this report).

The parameter values chosen for the model test case are:

$$
\begin{aligned}
\overline{\mathrm{Vd}}_{1} & =1.0 \mathrm{~cm} \mathrm{~s}^{-1}, \\
\overline{\mathrm{Vd}_{2}} & =0.1 \mathrm{~cm} \mathrm{~s}^{-1}, \\
\lambda_{1} & =5 \mathrm{~m}^{-1}, \\
\lambda_{2} & =250 \mathrm{~m}^{-1}, \\
r_{12} & =0.02 \mathrm{hr}^{-1},
\end{aligned}
$$

The dry-deposition velocities used are the same as those used by Sheih. (15) Values were obtained on the basis of observation and experiment given by Owers and A. W. Powe 11, (16) and Smith and Jeffries. (17)

The value of $\lambda_{1}$, the scavenging parameter for $\mathrm{SO}_{2}$, was selected from calculations made with experimental data by Dana, Hales and Wolf.(18) Values calculated from the data from independent experiments ranged from $2 \mathrm{~m}^{-1}$ to $10 \mathrm{~m}^{-1}$.

The value of $\lambda_{2}$, the scavenging parameter for sulfate, was derived by using simultaneously reported water concentration and average air concentration values of sulfate $\left(2.9 \mathrm{mg} 1 \mathrm{ter}^{-1}\right.$ and $8.3 \mu \mathrm{g} \mathrm{m}^{-3}$, respectively) in 
the Air Quality and Stationary Source Emission Control Report ${ }^{(1)}$ for a New Hampshire location. Using an average value of $0.7 \times 10^{-3} \mathrm{~m}^{-1}$ for $\mathrm{z}^{-1}$ (see Equation (5) and Table 2), a value of $250 \mathrm{~m}^{-1}$ is obtained for $\lambda_{2}$. This value is consistent with the value obtained by Dana and Hales ${ }^{(19)}$ where frontaltype rainfall is assumed to have values of 0.1 and $2.5 \mathrm{~mm}$ for geometric mean particle radius and geometric standard deviation.

The transformation rate used is consistent with those used by other modelers. Egan, Rao and Bass ${ }^{(20)}$ show the ir model predicts too much sulfate if a transformation rate of $0.02 \mathrm{hr}^{-1}$ is used and not enough if $0.01 \mathrm{hr}^{-1}$ is used. Sheih ${ }^{(15)}$ uses $0.023 \mathrm{hr}^{-1}$. Values inferred from analysis of experimenta 1 data (see Roberts and Friedlander (21) or Alkezweeny and Powe11 ${ }^{(22)}$ ) were found by Levy, Drewes and Hales ${ }^{(23)}$ to range from 0 to $0.55 \mathrm{hr}^{-1}$. The higher values were generally deduced from data taken from urban areas. Obviously the mechanisms of transformation will have to be better understood, as well as their distribution in time and space, before such experimentally derived results can be directly used.

\section{CONTRIBUTION OF $\mathrm{H}_{2} \mathrm{SO}_{4}$ DISSOCIATION TO RAINFALL ACIDITY}

The Air Quality and Stationary Source Emission Control Report, (1) contains a map of annual averages of $\mathrm{pH}$ of rainfall from several measuring points in the eastern United States for a period within 1965-66. A similar map for 1973-74 is given by Likens. (24) Minimum values shown on these maps are 4.2 and 4.1 , respectively.

The $\mathrm{pH}$ values appearing on these maps are long-term averages. Similarly the equation for $\mathrm{pH}$ to be derived below is intended for long-term averages over many individual showers. To derive the equation, the hydrogen ion mass from one plume element is calculated as shown, along with the diluting water volume from rain. Then, this calculation is summed over the many plume elements passing over a given sampling grid square during rains and is added to a base level to obtain a pH number for each sampling grid unit for the assessment period. 
The hydrogen ion content is assumed to come from $100 \%$ dissociation of atmospheric $\mathrm{H}_{2} \mathrm{SO}_{4}$ into $2 \mathrm{H}^{+}$and $\left(\mathrm{SO}_{4}^{=}\right)$and from a specified level that is derived from the presence of other compounds.

The rate of wet removal of sulfate from one plume element is:

$$
Q_{2}(t) \lambda_{2} p^{i j}(t) \quad\left(\mu g ~ h r^{-1}\right)
$$

The mass of sulfate removed by rainfall in one sampling period $(t)$ is:

$$
Q_{2}(t) \lambda_{2} p^{i j}(t) \Delta t \quad(\mu g) \quad
$$

Since there are 96 grams of sulfate per mole, the number of moles removed is:

$$
Q_{2}(t) \lambda_{2} p^{i j}(t)\left(10^{-6} / 96\right)=1.04 \times 10^{-8} Q_{2}(t) \lambda_{2} p^{i j}(t) \Delta t .
$$

Since there are two hydrogen ions for each sulfate ion, number of moles of hydrogen ions in the same water volume is:

$$
2.08 \times 10^{-8} Q^{2}(t) \quad \lambda_{2} P^{i j}(t) \Delta t \quad\left(\text { moles } H^{+}\right)
$$

To calculate the volume of water involved, the horizontal dimension of each plume element is assumed to be the area of the grid square it is located over. Using this assumption, the amount of water is $A^{i j p^{i j}}(t) \Delta t\left(m^{3}\right)$ or $10^{3} A^{i j} p^{i j} \Delta t$ (1iters). Thus, the hydrogen ion concentration is given by:

$$
\begin{aligned}
{\left[H^{+}\right] } & =\frac{2.08 \times 10^{-8} Q_{2}(t) \lambda_{2} p^{i j}(t) \Delta t}{10^{3} A^{i j} p^{i j}(t) \Delta t} \\
& =\frac{2.08 \times 10^{-11} Q_{2}(t) \lambda_{2}}{A^{i j}}\left(\frac{\text { mole }}{\text { liter }}\right) .
\end{aligned}
$$


For the entire simulation, the $\mathrm{pH}$ at grid square $i, j$ is calculated by summing the contributions of many plume elements that happened to be over the square during the hours of rain. Each of these contributions must be weighted by the rainfall rate of the hour, $P^{i j}(t)$. Because a base level of hydrogen ion concentration from other constituents is involved, the final equation for $\mathrm{pH}$ can be written as follows:

$$
p H^{i j}=-\log _{10}\left[\text { Base }+2.08 \times 10^{-11} \lambda_{2} \frac{t^{\sum Q_{2}(t) P^{i j}(t)}}{A^{i j} \sum p^{i j}(t)}\right]
$$

Equation (31) states that under the employed assumptions, $\mathrm{pH}$ is a function of vertically integrated sulfate concentration and scavenging efficiency. Since the number of plume elements passing over the area $A^{i j}$ depends on the magnitude of the area, the apparent dependence on $A^{i j}$ should cancel out if the assessment period is divided into a sufficiently large number of individual sampling periods.

The base concentration selected for these runs was $10^{-5.6}$ moles of hydrogen ion per liter, which is given by Likens ${ }^{(24)}$ as a representative value for the contribution of $\mathrm{CO}_{2}$ alone to acidity. Another significant contribution, that from nitrates, is taken into account later. 


\section{MODEL RESULTS}

\section{TEST SIMULATION DATA}

The model required three different types of data: wind, precipitation, and emission. In addition to discussing these data, this section discusses model testing observations.

Wind Data

Transport calculations were made with radiosonde data from selected groups of stations shown in Figure 1. The winds at each grid point were calculated by computing an average wind at each station through the layer 100 to $1000 \mathrm{~m}$ above the surface and then interpolating values to the grid intersections. The interpolation technique is based on the weighted average wind values of the three-to-five stations closest to each grid intersection. The weighting factor selected was the inverse square of the distance of the station from the grid intersection. Horizontal winds from any other interpolation scheme could be used.

\section{Precipitation Data}

Al1 simulations presented made use of the sequential hourly precipitation data for April 1974. The data used were derived from records of 777 cooperative observing stations of the National Climatic Center (NCC) and a small number of Atmospheric Environment Service stations (AES) in Canada as shown in Figure 3. Data for each hour were processed, using an inverse-square distance-weighting interpolation program discussed above, to provide values for each square on the 60 by 40 grid within a resolution of approximately $34 \mathrm{~km}$.

Emissions Data

A $1974 \mathrm{SO}_{2}$ emissions inventory was developed from 1973 National Emissions Data System data ${ }^{(25)}$ and 1974 data from the Federal Power Commission. (26) The inventory listed 60 sources: 40 utility and 20 nonutility. This inventory contains the largest $\mathrm{SO}_{2}$ emission sources in the U.S. portion of the grid, which accounts for approximately $65 \%$ of emissions over the grid. 


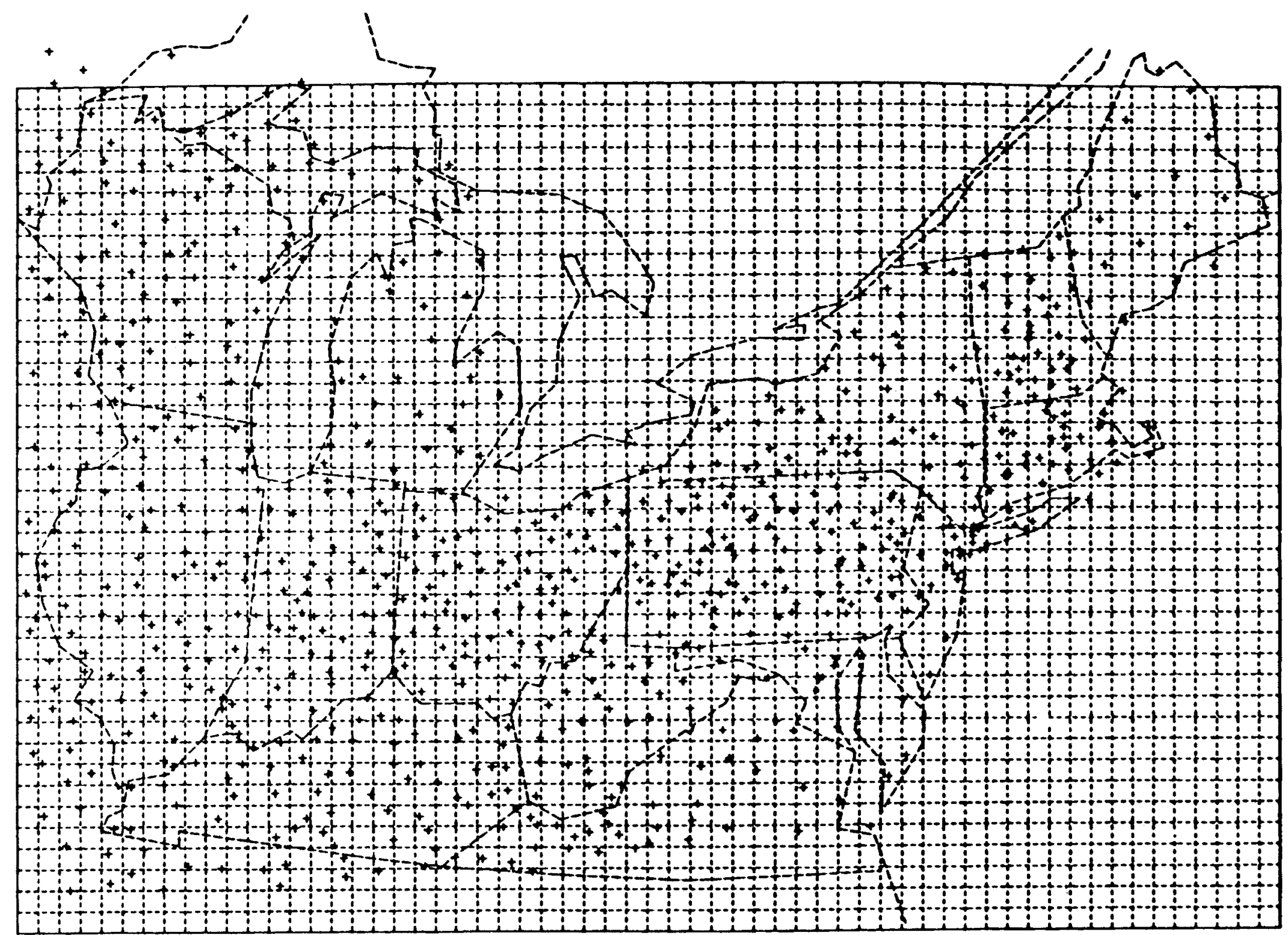

FIGURE 3. U. S. Precipitation Station Distribution and Sampling Grid 
Owing to lack of data and high source-to-source variability of sulfate emissions, all sulfate in this test was assumed to be generated by $\mathrm{SO}_{2}$ transformation.

This study of $\mathrm{SO}_{2}$ considered all sources to be point sources with a specified emission height. Nonutility sources were modeled as surface sources and utilities were modeled with an effective release height of $400 \mathrm{~m}$. Each utility and nonutility source in the inventory represents one actual emission source or a combination of emission sources located close together. Inventory approximations reduced computational costs during model development. The model can use different emission heights for each source.

Figure 4 gives the locations and relative strength of the $\mathrm{SO}_{2}$ emission sources. Emission strengths are depicted in the figure by circle diameters. The largest sources are on the order of $650 \times 10^{3}$ tons/yr. Observations for Model Testing

Average sulfate concentrations for April 1974, published as part of EPRI Design of the Sulfate Regional Experiment (SURE) I study, ${ }^{(27)}$ were selected for preliminary model comparisons. The sulfate data were obtained from the National Aerometric Sampling Network (NASN) and the EPRI SURE I monitors. The EPRI SURE I monitors were selected from an existing monitoring network to represent regional sulfate patterns. For initial analysis $\mathrm{SO}_{2}$ data were not considered since observations were more likely to be dominated by local sources unresolved by the regional model.

Using monthly sulfate concentrations limits application of statistical comparisons with model results to qualitative guidelines. This is because of monitoring site location, data quality, small sample sizes, and model predictions close to the no ise level of ambient measurements. In this study almost $85 \%$ of the monitoring sites were located in urban areas where higher concentrations of sulfate are caused by effects not explained by the model. For example, higher $\mathrm{SO}_{2}$-to-sulfate conversion rates occur in urban areas $(22)$ than in rura 1. (28) Measurement uncertainty caused by $\mathrm{SO}_{2}$ interference on the hi-vol filters used in sulfate monitoring is another problem with the sulfate data. (21) Monthly average concentrations taken from 24 observations 


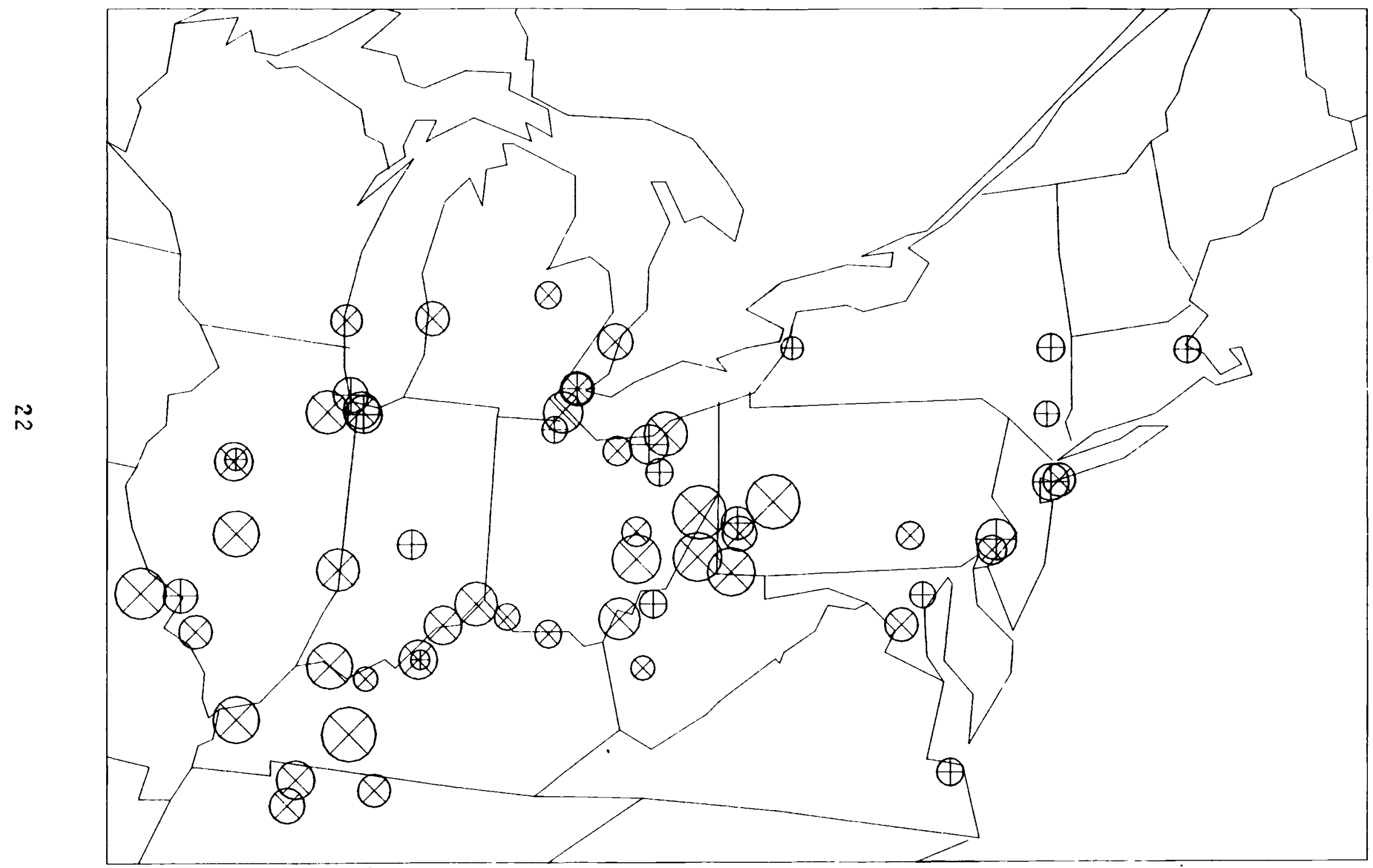

FIGURE 4. Source Distribution: Utility; Nonutility 
2-to-5 days/mo contributed to NASN data uncertainty. This uncertainty must be considered when interpreting verification statistics for comparison with other models. Results presented in this study are based on monthly averages of hourly values rather than predictions during short episodes when pronounced variations in spatial concentration fields would be expected. Finally the interpretation and effectiveness of verification statistics are limited by using predicted results from periods when observations are close to the noise level.

\section{TEST-CASE RESULTS}

A base case simulation was performed to provide both a demonstration of model capabilities and also a reference point for sensitivity studies. Input parameters, including emissions and meteorological data, for the simulation and data used for comparison are discussed in the previous sections. Two important features of the analysis are the use of a limited emissions inventory, which accounts for approximately $61 \%$ of U.S. $\mathrm{SO}_{2}$ emissions on the grid and also the use of a constant $\mathrm{SO}_{2}$-to-sulfate transformation rate of $2 \% / \mathrm{hr}$.

Model simulated spatial patterns coming from the data fields are presented in Figures 5 through 8 . These figures depict contoured results on a calculation-grid region map. The contours were smoothed by using a weighted average concentration of the grid square in question and the eight surrounding grid squares.

Sulfur dioxide concentration patterns shown in Figure 5 have areas of high concentrations that correspond to the area of highest emissions (see Figure 4 ). Low concentrations are near the grid boundaries. Peak concentrations of 30 to $60 \mathrm{\mu g} \mathrm{\textrm {m } ^ { - 3 }}$ occur in the vicinity of the largest ground-level or nonutility sources in the Chicago-Gary area, New York City, Philadelphia, the ClevelandAkron area, and near elevated utility sources in southwestern Pennsylvania. Higher concentration levels are also predicted in the vicinity of other large utility sources. These results are consistent with expectations of $\mathrm{SO}_{2}$ plume behavior, which produces maximum concentrations within about $10 \mathrm{~km}$ of the sources in most cases. 


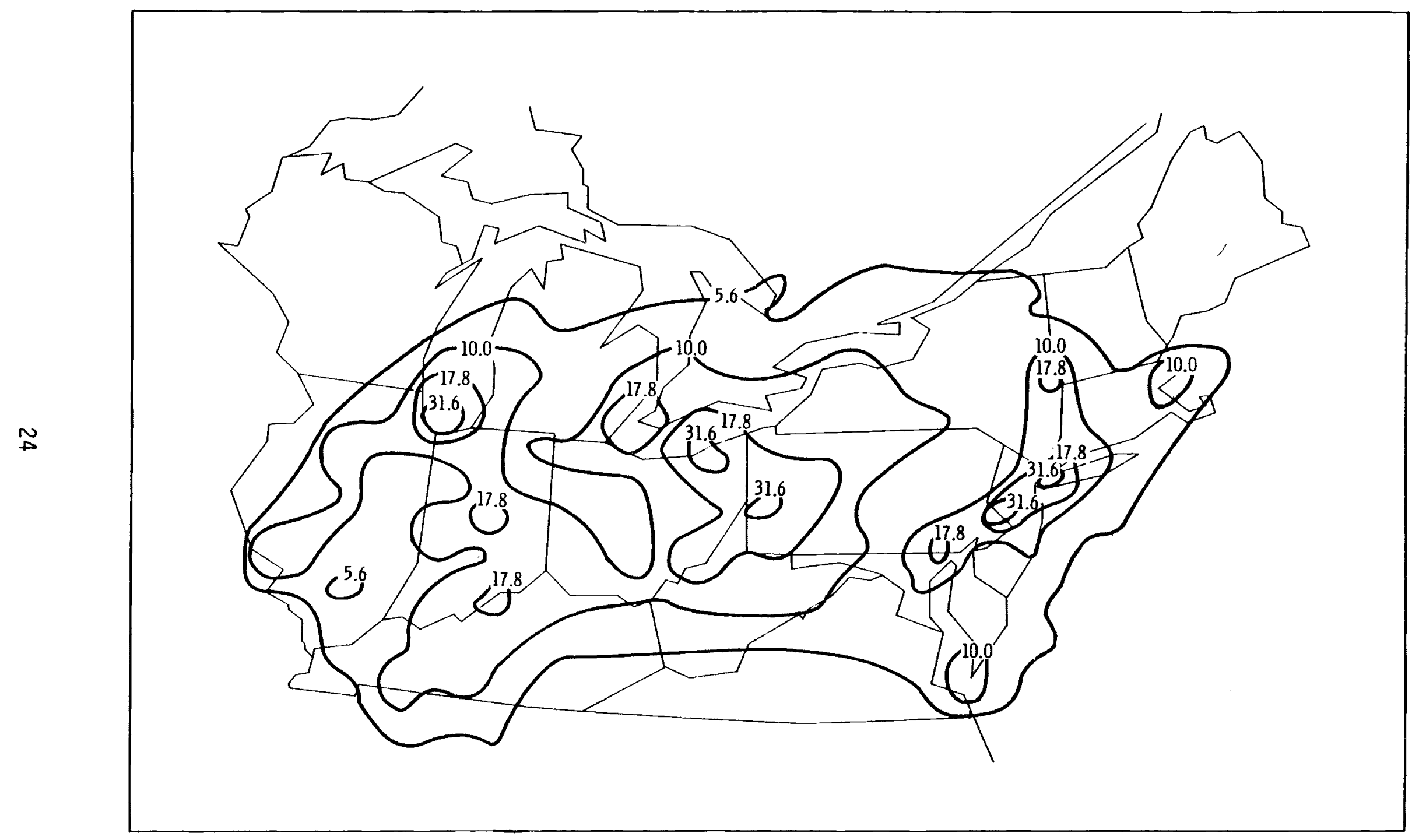

FIGURE 5. Predicted Average Ground-Level Air Concentrations for $\mathrm{SO}_{2}, \mu \mathrm{g} \mathrm{m}^{-3}$ 


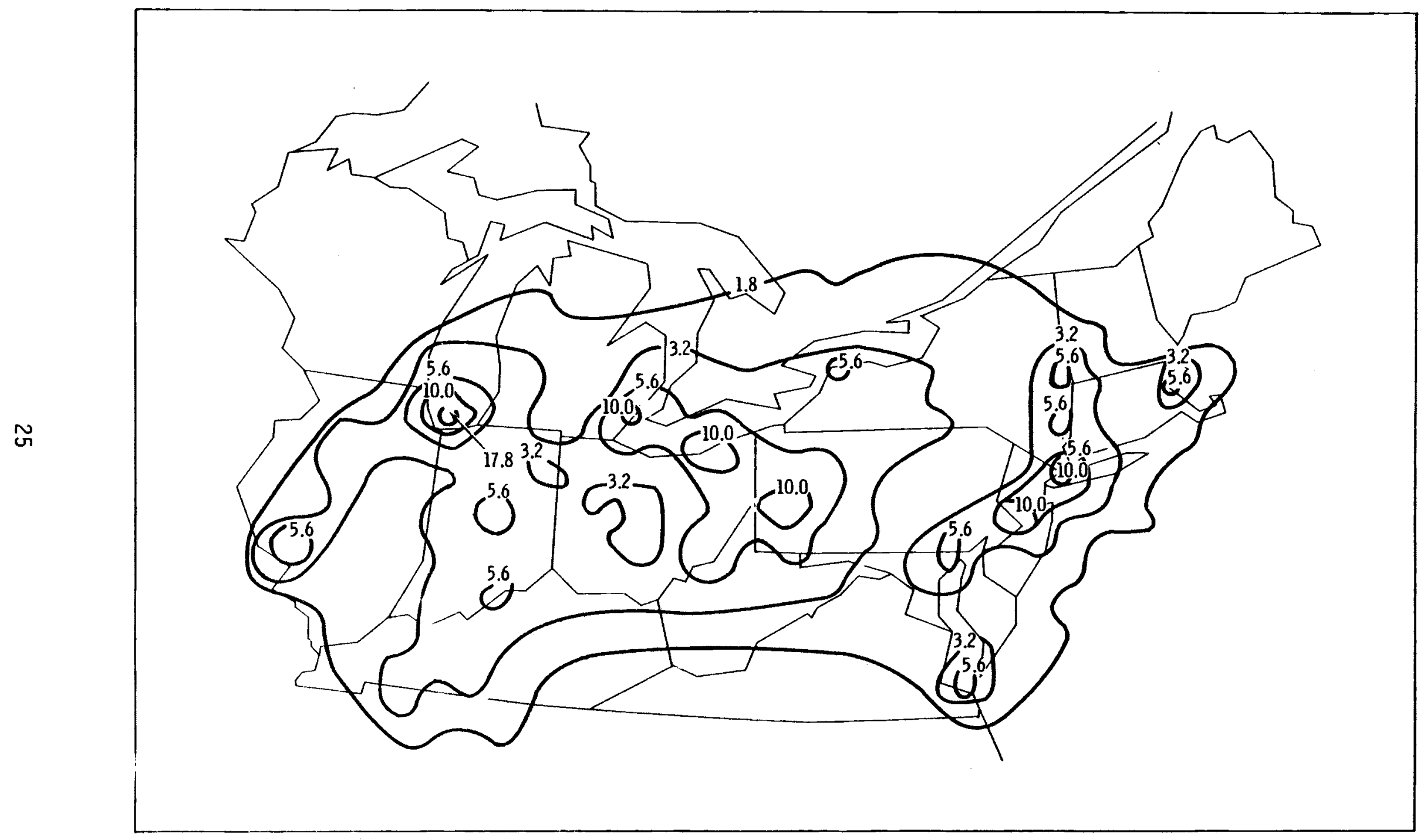

FIGURE 6. Predicted Average Deposition Rate for $\mathrm{SO}_{2}, \mathrm{~g} \mathrm{~m}^{-2} \mathrm{yr}^{-1}$ 


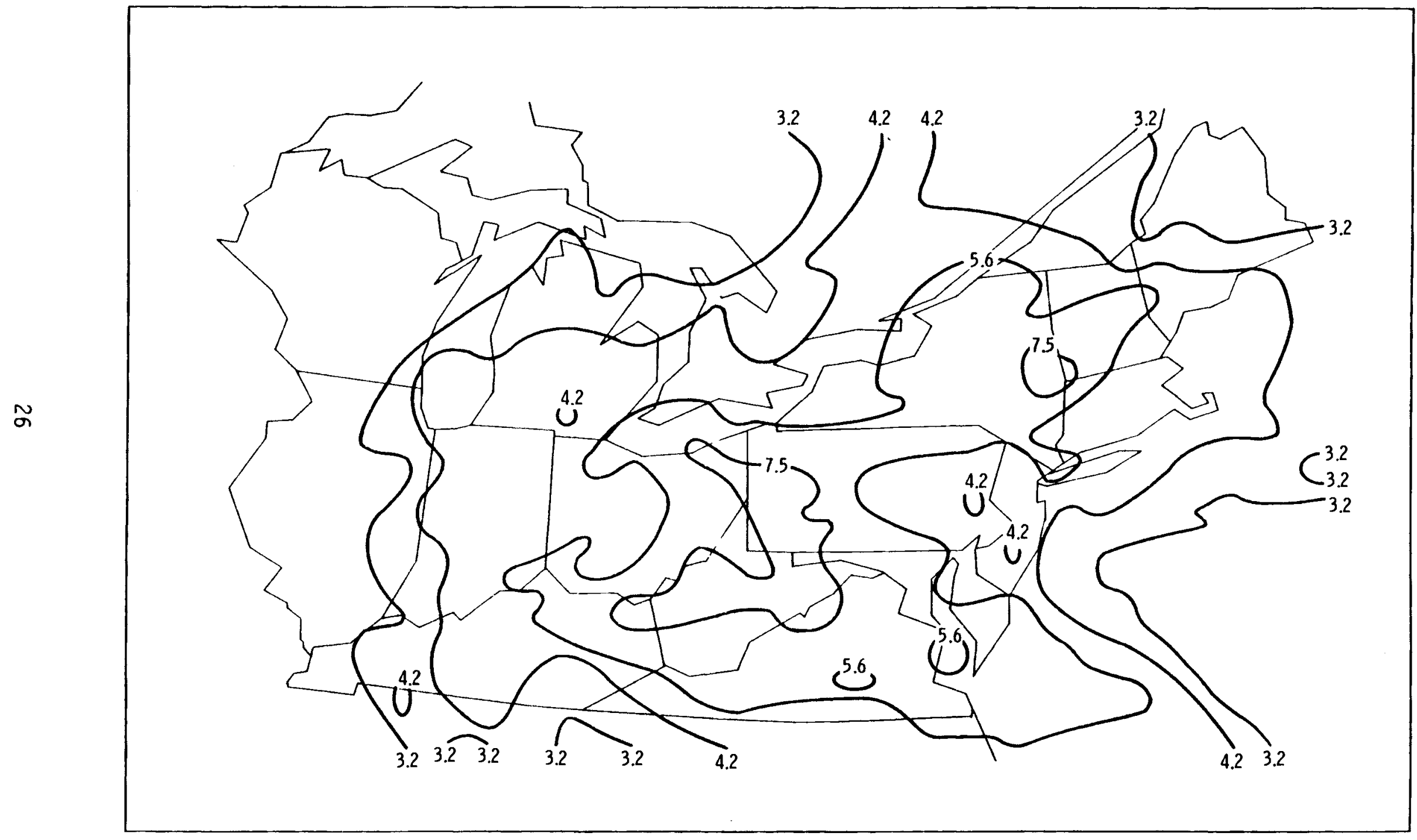

FIGURE 7. Predicted Average Ground-Level Air Concentrations of Sulfate, $\mu \mathrm{g} \mathrm{m}^{-3}$ 


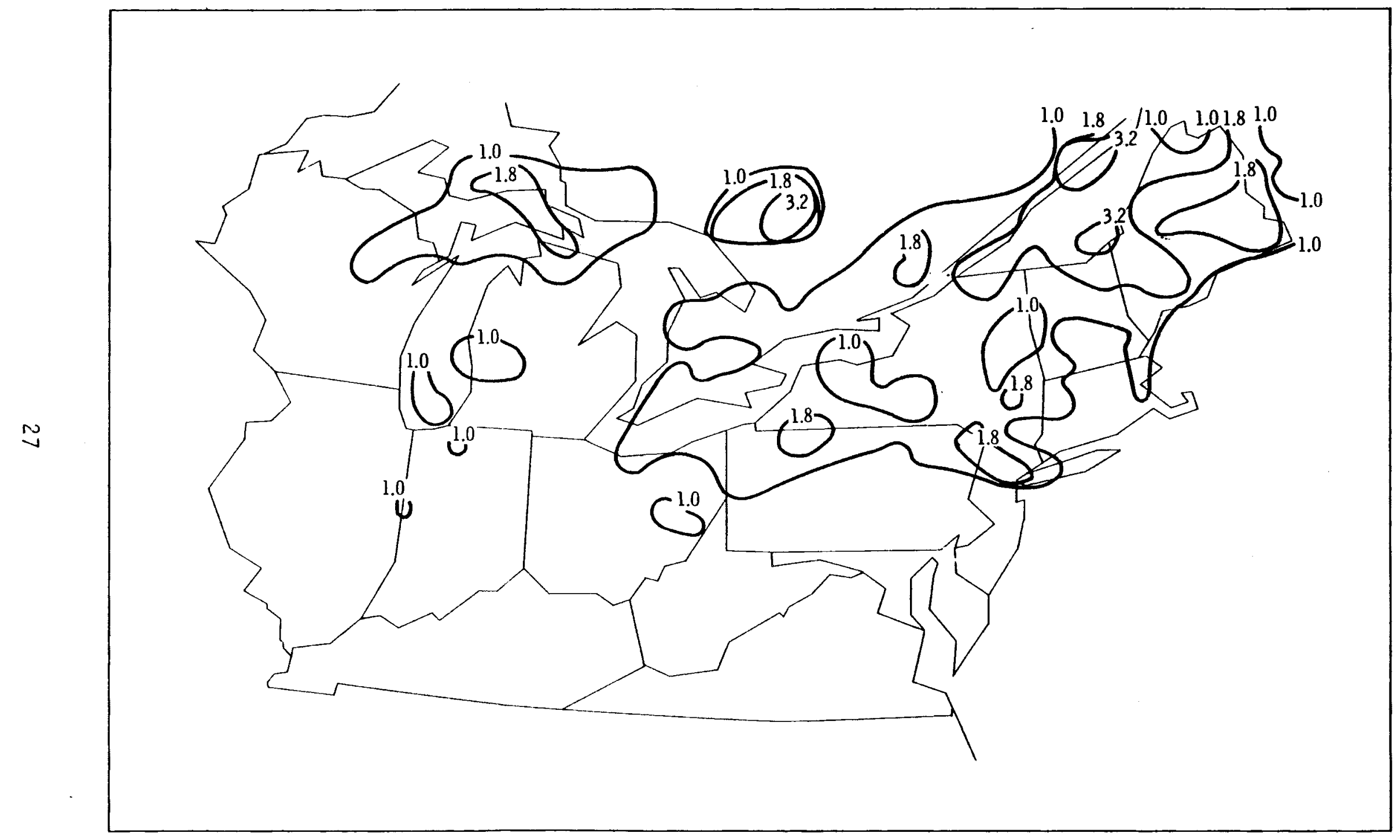

FIGURE 8. Predicted Average Deposition Rate for Sulfate, $\mathrm{g} \mathrm{m}^{-2} \mathrm{yr}^{-1}$ 
Predicted monthly average $\mathrm{SO}_{2}$ concentrations, which have a maximum monthly average of $61 \mathrm{\mu g} \mathrm{m}^{-3}$, fall within the same range as observed concentrations. (This can be compared to an annual National Ambient Air Quality Standard of $80 \mathrm{\mu g} \mathrm{m}^{-3}$.) Selected observed data from the EPRI SURE I report $(27)$ and predicted $\mathrm{SO}_{2}$ concentration decrease with regard to distance from individual sources. Therefore, most $\mathrm{SO}_{2}$ maxima can be considered subgrid scale effects relative to the model.

$\mathrm{SO}_{2}$ deposition patterns (see Figure 6 ) demonstrate the same sourcerelated behavior as $\mathrm{SO}_{2}$ concentrations. Maximum deposition values of 10 to $20 \mathrm{~g} \mathrm{~m}^{-2} \mathrm{yr}^{-1}$ are predicted near the largest ground-level emission sources. The close correspondence between predicted concentrations and deposition patterns indicates that in the current mode 1 configuration constant drydeposition velocity effects dominate $\mathrm{SO}_{2}$ removal rather than wet processes.

Average sulfate concentrations (see Figure 7) are distributed in a broad pattern that cannot be related to a single source complex. The dominant feature in the figure is a large area of concentrations in the range of 6 to 10 $\mu \mathrm{g} \mathrm{m}^{-3}$, which covers most of the mid-Atlantic states and parts of New England and Ohio. The relative smoothness of the pattern, as compared to that of $\mathrm{SO}_{2}$, occurs because sulfate is formed as a secondary pollutant along the trajectories.

April 1974 test-case results were compared to observed concentrations. Data from a mix of 107 urban and nonurban sites provided a spatial average concentration of $9.8 \mathrm{ug} \mathrm{m}^{-3}$. Predicted concentrations at the same locations averaged $5.2 \mathrm{\mu g} \mathrm{m}^{-3}$. Thus, $53 \%$ of the observed sulfate is predicted from $61 \%$ of the $\mathrm{SO}_{2}$ emissions inventory. The maximum observed and predicted monthly average concentrations differed by a similar factor with values of 18 and $10.5 \mathrm{ng} \mathrm{m}^{-3}$, respectively. A linear correlation-regression analys is indicated a positive correlation of 0.43 between observed and predicted concentrations and a regression equation with a slope of 0.26 and an intercept of $2.65 \mu \mathrm{g} \mathrm{m}^{-3}$. Fifty-seven percent of all predicted concentrations were within a factor of two of observed value, and $87 \%$ were within a factor of 
three. The remaining $10 \%$ of the values were predictions at sites on the western boundary of the emission grid where no upwind sources were given for the prevailing wind direction.

Much of the variation between observed and predicted concentrations can be attributed to the basic model concept and the emissions used as model input. Because the model is Lagrangian, no allowance is made for pollutant mass entering the sampling grid from outside the grid boundaries. In addition, the mode 1 is not capable of predicting subgrid scale $(\sim 30 \mathrm{~km})$ air quality effects as pointed out in the discussion of maximum $\mathrm{SO}_{2}$ concentrations. Also, the Lagrangian model makes verification for the complete inventory prohibitive because of individual treatment of all sources. The 60 -source base inventory represents approximately $60 \%$ of the U.S. $\mathrm{SO}_{2}$ emissions on the grid. As the number of ranked sources increases, the rate of change for the fraction of total emission decreases. For example, increasing the number of sources from 60 to 70 increases the emission fraction only a few percentages.

By examining the rough analysis of observed sulfate data for Apri1 1974 (see Figure 9) an additional, more qualitative form comparison can be made. As noted earlier, predicted concentrations are lower than observed concentrations, although the patterns are similar. The primary pattern difference is: higher observed concentrations on the Atlantic Coast between New York City and Baltimore, probably because of urban influences in the data unresolved by the model.

Maximum values for sulfate deposition patterns shown in Figure 8 predominate over the northeast quadrant of the grid rather than over the central portion as was the case for sulfate concentrations. This observation, as well as the irregular sulfate-deposition pattern, indicates the importance of wetremoval processes in the modeling of sulfate deposition. Modification of rainfall pH also shows the same pattern (see Figure 10) with high rainfall acidity in the northeast grid quadrant. The distribution correlates fairly well with the 1972-73 map given by Likens. (24) However, there is a considerable extension of low pH down into the Ohio River areas shown by Likens that does not appear on this prediction map. 


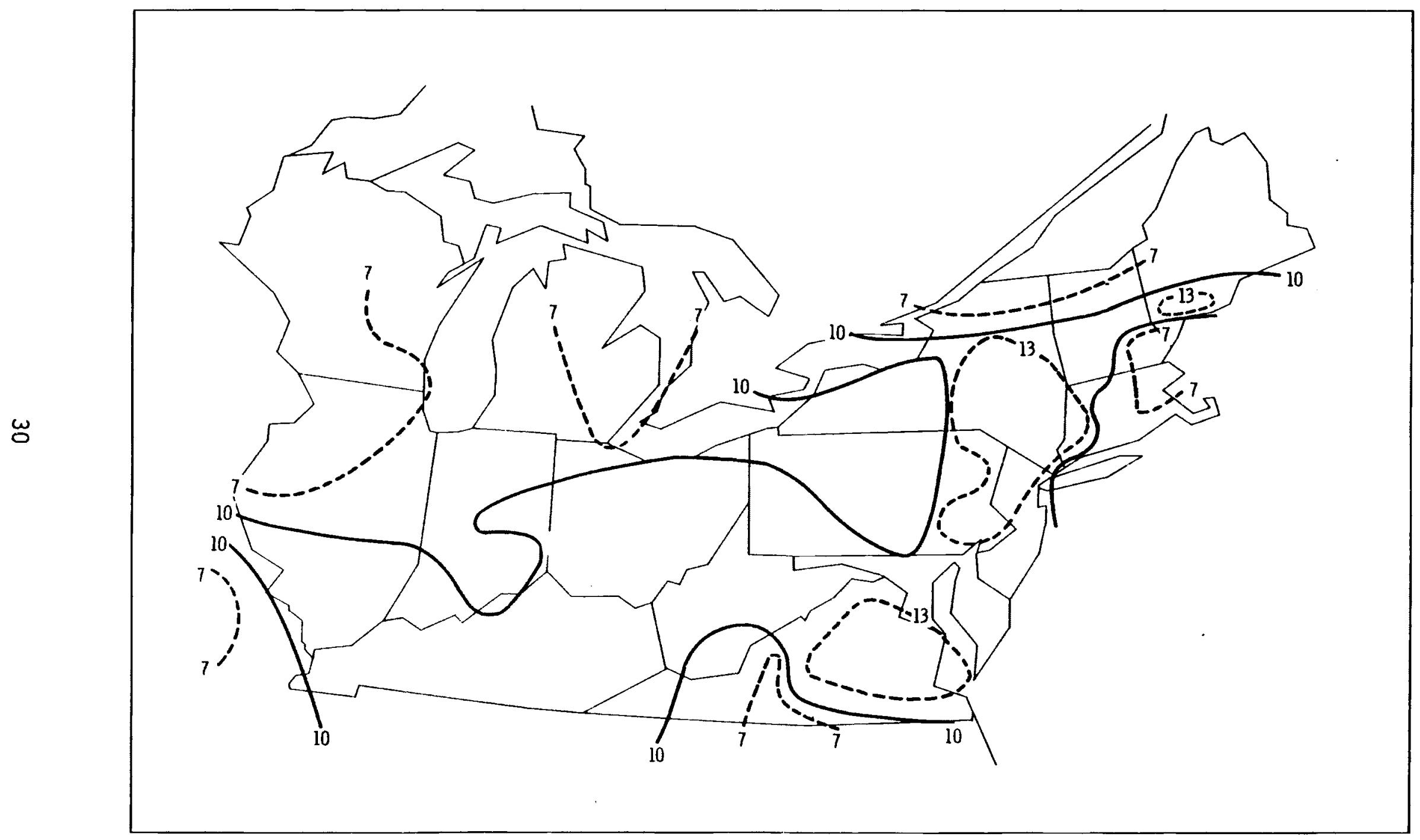

FIGURE 9. Observed Average Ground-Level Air Concentrations of Sulfate, $\mu \mathrm{g} \mathrm{m}^{-3}$ 


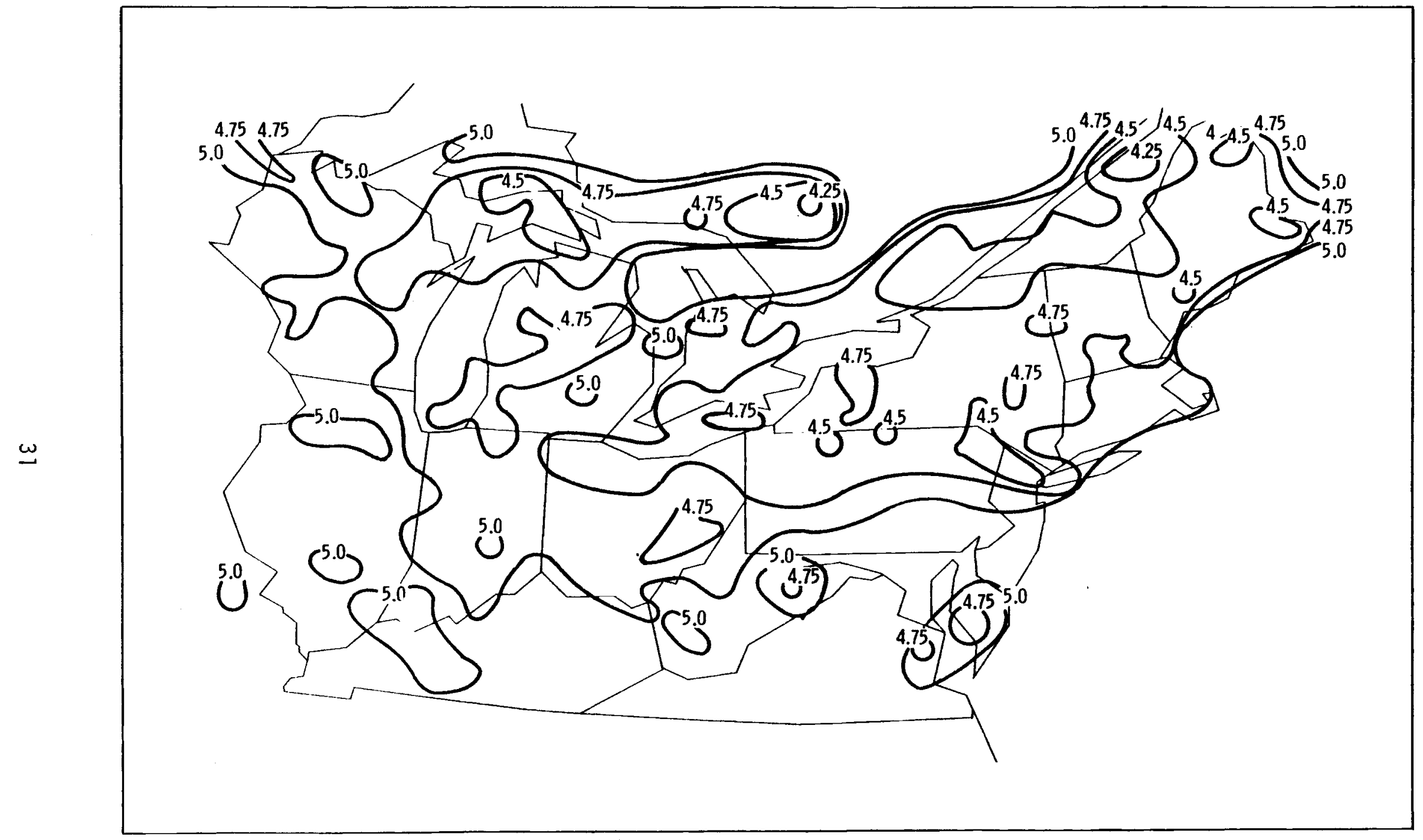

FIGURE 10. Predicted Average pH of Rainfall 
Chiefly because of differences in the Ohio Valley, the average $\mathrm{pH}$ on Figure 10 is approximately 0.3 higher than the average $\mathrm{pH}$ on the map by Likens. This difference is acceptable since the sulfur-compound-emissions inventory used represents only $61 \%$ of the anthropogenic sulfur-compound emissions, and since sulfur compound emissions according to Likens ${ }^{(24)}$ constituted on $1 y$ 66\% of the total contribution to ambient acidity, $30 \%$ being from nitrates. Therefore, the $\mathrm{SO}_{2}$ emissions inventory used consists of not more than $40 \%$ of the total contribution to ambient acidity and average predicted $\mathrm{pH}$ value based on this inventory should be about 0.4 higher than the ambient $\mathrm{pH}$. To aid in the interpretation of sensitivity test results, discussed in the following section, a mass-balance summary for the base test-case has been compiled in Table 1. The table shows $\mathrm{SO}_{2}$ and sulfate mass left in the air over the grid at the completion of simulations, total deposition, and the pollutant mass that escapes the grid for elevated utility sources and for the total inventory.

Table 1, which involves utility as we 11 as total inventory effects, shows the final fate of sulfate emissions with roughly $52 \%$ of emissions being

TABLE 1. Mass Balance Summary

Fraction of $\mathrm{SO}_{2}$ Emissions, $\%$
All Sources

Mass remaining on computational

grid

$\begin{array}{lll}\mathrm{SO}_{2} & 2.4 & 2.8 \\ \text { Sulfate } & 1.0 & 1.1\end{array}$

Deposition

$\mathrm{SO}_{2}$

Sulfate

Transport off grid

$\mathrm{SO}_{2}$

Sulfate
21.9

22.4
37.9

10.1
43.3

2.8
1.1 
deposited on the grid and $44 \%$ being transported beyond the grid boundaries. Figure 6 shows most of the $\mathrm{SO}_{2}$ deposition is near the emission source while sulfate deposition is at a greater distance from the source. Deposition values in Table 1 indicate that $\mathrm{SO}_{2}$ deposition fraction increases as groundlevel sources are added, which probably indicates increased $\mathrm{SO}_{2}$ removal. Emission transport off the grid demonstrates the same effects. With elevated sources, $\mathrm{SO}_{2}$ deposition is less, allowing more $\mathrm{SO}_{2}$ and sulfate mass to escape the grid.

\section{SENSITIVITY ANALYSIS RESULTS}

Sensitivity testing indicates which physical processes need to be specified with greater sophistication and which modeling approximations are more tolerable than others. Sensitivity testing also provides some insight into how predictive capabilities can be improved.

The first sensitivity testing approximation for ground-level concentrations is a simple study of the differential equations for the time rate-ofchange of mass [Equations (12-15)] with values substituted from Equations $(19-25)$, so that

$$
\begin{aligned}
& \frac{d Q_{1}}{d t}=-\left(36 Z^{-1}+5 P+0.02\right) Q_{1} \\
& \frac{d Q_{2}}{d t}=-\left(3.6 Z^{-1}+250 P\right) Q_{2}+0.03 Q_{1},
\end{aligned}
$$

when time is in hours. The first terms on the right are the dry-deposition rate; the second terms are the wet-deposition rate; and the third terms are the chemical-transformation rate.

Both typical and extreme magnitudes of the separate terms need to be considered. Average $\mathrm{z}^{-1}$ values differ according to whether the release is an elevated utility release or a ground-level nonutility release. Average $z^{-1}$ 
values were calculated using the 10 utility and the 10 nonutility sources with the highest emission rate (see Table 2).

TABLE 2. Average Values of Vertical Distribution Factor $\left(z^{-1}\right)$

\begin{tabular}{|c|c|c|c|}
\hline & $\mathrm{H}$ meters & for $\frac{z^{-1} 10}{\mathrm{SO}_{2}}$ & $\frac{r^{-1}}{\text { for }}\left(\mathrm{SO}_{4}=\right)$ \\
\hline $\begin{array}{l}\text { Utility } \\
\text { Urban }\end{array}$ & $\begin{array}{r}400 \\
0\end{array}$ & $\begin{array}{l}0.53 \\
1.7\end{array}$ & $\begin{array}{l}0.58 \\
1.1\end{array}$ \\
\hline
\end{tabular}

Average values can be substituted into Equations (32) and (33), along with a climatological precipitation rate of $10^{-4} \mathrm{~m} \mathrm{hr}^{-1}$, so that

$$
\begin{aligned}
& \frac{\mathrm{dQ}_{1}}{\mathrm{dt}}=-\left(\left\{\begin{array}{l}
0.02 \\
0.06
\end{array}\right\}+0.0005+0.02\right) \mathrm{Q}_{1}, \\
& \left.\frac{\mathrm{dQ}_{2}}{\mathrm{dt}}=-\left(\begin{array}{l}
0.002 \\
0.004
\end{array}\right\}+0.025\right) \mathrm{Q}_{2}+0.03 \mathrm{Q}_{1},
\end{aligned}
$$

This parameterization implies that for the climatological case wet deposition of $\mathrm{SO}_{2}$ and dry deposition of sulfate can be neglected. However, for extreme episodes these two magnitudes could be important. For example, if the precipitation rate during a particular hour is $0.025 \mathrm{~m} / \mathrm{hr}$, the wet-removal rate for $\mathrm{SO}_{2}$ is $0.0125 \mathrm{~m} \mathrm{hr}^{-1}$, which is comparable to the climatological dry-removal rate. Another extreme case for dry deposition occurs when the mean wind speed is small, about $2 \mathrm{~m} \mathrm{sec}^{-1}$, and very stable conditions prevail. In this case, the dry-removal rate for sulfate from ground-level source is calculated at 0.07 for the first hour (if an hourly time step is used). From these observations all five of the removal parameters are important for episode-type assessments. On the other hand, model sensitivity is greater for transformation rate, dry-removal rate of $\mathrm{SO}_{2}$, and wet-removal rate of sulfate than for wet deposition of $\mathrm{SO}_{2}$ or dry deposition of sulfate in both long and short-term predictions. 
Actual modeling sensitivity tests include studies of nine modeling changes as compared to the base-test case previously discussed. These changes inc Tude:

- using a fixed mixing depth rather than a variable one

- lowering the maximum mixing depth from $1500 \mathrm{~m}$ to $1000 \mathrm{~m}$ while using the variable mixing depth

- using neutral stability during all time periods

- studying the effects of changes in dry deposition-velocity for $\mathrm{SO}_{2}$ over the range from $2.0 \mathrm{~cm} \mathrm{sec}^{-1}$ to $0.5 \mathrm{~cm} \mathrm{sec}^{-1}$

- varying sulfate dry-deposition velocity from $0.1 \mathrm{~cm} \mathrm{sec}^{-1}$ to $0.2 \mathrm{~cm}$ $\sec ^{-1}$

- varying the $\mathrm{SO}_{2}$ wet-removal coefficient from $5 \mathrm{~m}^{-1}$ to $30 \mathrm{~m}^{-1}$

- studying the effects of reducing the sulfate wet-removal coefficient from $250 \mathrm{~m}^{-1}$ to $150 \mathrm{~m}^{-1}$ and to $25 \mathrm{~m}^{-1}$

- varying the $\mathrm{SO}_{2}$ to sulfate transformation rate in the range $0.01 \mathrm{hr}^{-1}$ to $0.04 \mathrm{hr}^{-1}$

- increasing the transformation rate during precipitation periods from 0.02 to $0.07 \mathrm{hr}^{-1}$, and decreasing it to $0.01 \mathrm{hr}^{-1}$.

The first three changes are modifications in the model that cannot be approximated by a simple parameter change. The last six changes represent effects caused by changes in pollutant removal parameters. Table 3 summarizes results of the sensitivity studies. The table lists the percent of change of average concentration and deposition values for the modified cases and corresponding values for the base test-case for all sources and for utility sources on ly.

Discussion of this table is limited to the most important features and focuses on utility emissions analysis. The most interesting comparison is between the variable stability base test-case and the constant (neutral) stability run. The $\mathrm{SO}_{2}$ ground-level air concentration and deposition are each 
TABLE 3. Sensitivity Test Results

Percent Change in Average Values From the Base Case

\begin{tabular}{|c|c|c|c|c|c|c|c|c|}
\hline \multirow{2}{*}{$\begin{array}{l}\text { Fractional } \\
\text { Parameter } \\
\text { Change } \\
\end{array}$} & \multicolumn{2}{|c|}{$\begin{array}{c}\mathrm{SO}_{2} \\
\text { Concentration } \\
\end{array}$} & \multicolumn{2}{|c|}{$\begin{array}{c}\mathrm{S}_{2} \\
\text { Deposition } \\
\end{array}$} & \multicolumn{2}{|c|}{$\begin{array}{c}\text { Sulfate } \\
\text { Concentration }\end{array}$} & \multicolumn{2}{|c|}{$\begin{array}{l}\text { Sulfate } \\
\text { Deposition }\end{array}$} \\
\hline & Sources & Utility & Sources & Utility & Sources & Utility & Sources & Utility \\
\hline & 1.0 & 3.3 & 0.8 & 3.0 & 17.3 & 20.6 & 3.2 & 3.1 \\
\hline 0.66 & 10.7 & 12.9 & 10.3 & 12.3 & 20.3 & 21.7 & -0.2 & -0.1 \\
\hline & 22.8 & 28.2 & 21.8 & 27.7 & 73.5 & 68.4 & 4.8 & 2.8 \\
\hline $\begin{array}{l}2.00 \\
0.50\end{array}$ & $\begin{array}{r}-30.5 \\
25.3\end{array}$ & $\begin{array}{r}-26.4 \\
19.8\end{array}$ & $\begin{array}{r}41.8 \\
-37.3\end{array}$ & $\begin{array}{r}47.4 \\
-39.3\end{array}$ & $\begin{array}{r}-21.7 \\
17.5\end{array}$ & $\begin{array}{r}-18.5 \\
13.7\end{array}$ & $\begin{array}{r}-21.1 \\
16.7\end{array}$ & $\begin{array}{r}-18.7 \\
13.4\end{array}$ \\
\hline 6.00 & -4.7 & -5.4 & 9.2 & 11.6 & -2.9 & -3.1 & -6.9 & -7.0 \\
\hline 2.00 & 0.0 & 0.0 & 0.0 & 0.0 & -4.1 & -3.7 & 14.3 & 13.6 \\
\hline $\begin{array}{l}0.10 \\
0.60\end{array}$ & $\begin{array}{l}0.0 \\
0.0\end{array}$ & $\begin{array}{l}0.0 \\
0.0\end{array}$ & $\begin{array}{l}0.0 \\
0.0\end{array}$ & $\begin{array}{l}0.0 \\
0.0\end{array}$ & $\begin{array}{r}14.8 \\
3.8\end{array}$ & $\begin{array}{r}15.4 \\
4.0\end{array}$ & $\begin{array}{l}-59.4 \\
-16.1\end{array}$ & $\begin{array}{l}-60.2 \\
-16.3\end{array}$ \\
\hline $\begin{array}{l}0.50 \\
2.00\end{array}$ & $\begin{array}{r}14.5 \\
-20.7\end{array}$ & $\begin{array}{r}17.5 \\
-24.5\end{array}$ & $\begin{array}{r}13.7 \\
-19.8\end{array}$ & $\begin{array}{r}16.8 \\
-23.7\end{array}$ & $\begin{array}{r}-43.6 \\
63.0\end{array}$ & $\begin{array}{r}-43.1 \\
60.5\end{array}$ & $\begin{array}{r}-43.4 \\
62.1\end{array}$ & $\begin{array}{r}-43.2 \\
61.1\end{array}$ \\
\hline 3.50 & -6.6 & -7.8 & -6.5 & -7.9 & 11.1 & 10.7 & 43.6 & 43.0 \\
\hline 0.50 & 1.7 & 2.1 & 1.7 & 1.7 & -3.3 & -2.8 & -11.4 & $-11.2^{\circ}$ \\
\hline
\end{tabular}


increased about $28 \%$ in the variable stability case, while the sulfate air concentration is increased 68\%; however, the sulfate deposition is increased only $3 \%$. Further runs were made, using the largest 10 utility sources, to determine what combination of parameterization caused the difference between the increase in $\mathrm{SO}_{2}$ deposition and sulfate deposition.

The results of the additional runs indicated that constant stability increases the predicted ground-leve $1 \mathrm{SO}_{2}$ concentrations. This difference in predicted ground-level concentrations occurs because most of the sulfate concentrations are from plume elements that passed through the afternoon period of unstable conditions, thus becoming more vertically extended. At the onset of constant stability $(C)$, the vertical distribution factor $\left(Z^{-1}\right)$ drops to about $60 \%$ of its former value. Because most of the plume elements are already producing significant ground-level concentrations even though the ir release height is $400 \mathrm{~m}$, the sudden vertical extension decreases the ground-level sulfate concentrations. On the other hand, much of the significant groundleve $1 \mathrm{SO}_{2}$ concentration is produced by plume elements that have not undergone this expansion.

By leaving the stabilities as originally prescribed, comparisons of ground-level air concentration of constant stability modeling to varying stability modeling can be changed by manipulating the deposition velocities. For example, if the deposition velocity for sulfate is increased to $1.0 \mathrm{~cm} \mathrm{sec}-1$ (thus equaling that for $\mathrm{SO}_{2}$, constant stability modeling increases both the $\mathrm{SO}_{2}$ and sulfate ground-leve 1 air concentrations by $29 \%$. However, this comparison retains the inequality between wet-deposition rates. Since the inequality exists, the two increased ratios cannot be said to be equal if the dry-and wet-deposition rates for both compounds are the same. If the deposition rates are the same, the ratio of increase for sulfate would be greater.

From these investigations of model sensitivity, the differences between ratio increases, when constant stability modeling is compared with variable stability modeling, are not likely to vanish unless the parameterization is uncharacteristic of atmospheric behavior. 
Table 3 also shows that the greatest sensitivity to parameter changes occurs with transformation and dry deposition of $\mathrm{SO}_{2}$. When the transformation rate in the ranges of experimental values is doubled from $2 \%$ to $4 \%$, the increase of sulfate ground-level air concentration and sulfate deposition is $60 \%$.

Another feature of the increases when constant stability modeling is compared to variable stability modeling is the difference between the increases of concentration and deposition when comparison is made between $\mathrm{SO}_{2}$ and sulfate. Both total concentration and deposition for $\mathrm{SO}_{2}$ increase by $28 \%$, but for sulfate the concentration increases $68 \%$ and the deposition $3 \%$. The reason for this difference is that dry deposition, which is proportional to ground-level concentration, dominates $\mathrm{SO}_{2}$ deposition, while wet deposition, which is proportional to the vertically-integrated concentration, dominates sulfate deposition. Therefore, the increase of deposition of $\mathrm{SO}_{2}$ matches the increase of ground-level air concentration. However, since there is more deposition of $\mathrm{SO}_{2}$, there is less of it available for transformation to sulfate. Therefore, wet deposition of sulfate is less while dry deposition of sulfate, being proportional to the ground-level air concentration, is more. Evidently the two effects largely cancel each other out. 


\section{REFERENCES}

1. N.A.S., Air Quality and Stationary Source Emission Control. Commission on Natural Resources, National Academy of Sciences, Washington, D.C. Prepared for Committee on Public Works, Senate, Washington, D.C., March 1, 1975.

2. M. C. MacCracken, The Multistate Atmospheric Power Production Pollution Study. Department of Energy Publication D0E/EV-0008/1, NTIS U.S. Department of Commerce, Springfield, VA, January, 1978.

3. R. M. Perhac, Sulfate Regional Experiment in Northeastern United States. Proceedings of the International Symposium on Sulfur in the Atmosphere, Dubrovnik, Yugos lavia, September 7-14, 1977.

4. D. Randerson, "Overview of Regional-Scale Numerical Models," Bull. of the Amer. Met. Soc., 57:797-804, 1976.

5. L. L. Wende11, "Mesoscale Wind Fields and Transport Estimates Determined from a Network of Wind Towers," Mon. Wea. Rev. 100:565-578, 1972.

6. H. Tennekes, "The Atmospheric Boundary Layer," Physics Today, 52-63, 1974.

7. B. Bolin and C. Persson, "Regional Dispersion and Deposition of Atmospheric Pollutants with Particular Application to Sulfur Pollution over Western Europe," Tellus XXVII, 3:281-310, 1975.

8. Lars P. Prahm, and Ove Christensen, "Long-Range Transmission of Pollutants Simulated by the 2-D Pseudospectral Dispersion Model," Journal of Applied Meteorology, 16:896-910. Sept. 1977.

9. D. J. Carson, "The Development of a Dry Inversion-Capped Convectively Unstable Boundary Layer," Quart. J. R. Met. Soc. 99:450-467, 1973.

10. A. Venkatram and R. Viskanta, Radiative Effects of Pollutants on the Planetary Boundary Layer. U.S. Environmental Protection Agency Report EPA-600/4-76-039, Office of Research and Development, Research Triangle Park, NC, 1976.

11. J. C. Kaimal, J. C. Wyngaard, D. A. Haugen, 0. R. Cote, Y. Izumi, S. J. Caughey and C. J. Readings, "Turbulence Structure in Convective Boundary Layer." J. Of the Atm. Sci. 33:2152-2169, 1976.

12. E. C. Eimutis and M. G. Konicek, "Derivations of Continuous Functions for the Lateral and Vertical Atmospheric Dispersion Coefficients," Atm. Env. $\underline{6}: 859-863,1972$. 
13. J. L. Heffter and G. J. Ferber, A Regional-Continental Scale Transport, Diffusion, and Deposition Mode 1 - Part II: Diffusion-Deposition Models. NOAA Techn ical Memorandum ERL ARL-50, Air Resources Laboratories, Silver Spring, MD, June 1975.

14. S. R. Doty, B. L. Wallace and G. C. Holzworth, A Climatological Analys is of Pasquill Stability Categories Based on "STAR" Summaries. Environmental Protection Agency, Environmental Sciences Research Laboratory, Research Triangle Park, NC, 1976.

15. C. M. Sheih, "Application of a Statistical Trajectory Mode 1 to the Simulation of Sulfur Pollution over Northeastern United States," Atm. Env. 11:173-178, 1977.

16. M. J. Owers and A. W. Powe11, "Deposition Velocity of Sulphur Dioxide on Land and Water Surfaces Using 35S Tracer Method," Atm. Env. 8: 3863-67, 1974.

17. F. B. Smith and G. H. Jeffrey, "Airborne Transport of Sulphur Dioxide from the U.K.," Atm. Env. 9:643-659, 1975.

18. T. M. Dana, J. M. Hales and M. A. Wolf, "Rain Scavenging of $\mathrm{SO}_{2}$ and Sulfate from Power Plant Plumes," $\mathrm{J}$. of Geo. Res. 80:4119-4129, 1975.

19. M. T. Dana and J. M. Hales, "Statistical Aspects of the Washout of Polydisperse Aerosols," Atm. Env. 10:45-50, 1976.

20. B. A. Egan, K. S. Rao and A. Bass, A Three-Dimensional AdvectiveDiffusive Model for Long Range Sulfate Transport and Transformation. 7th International Technical Meeting on Air Pollution Modeling and Its Application, Airlie, VA, September 7-10, 1976.

21. P. E. Roberts and S. K. Friedlander, "Conversion of $\mathrm{SO}_{2}$ to Sulfur Particulate in the Los Angeles Atmosphere," Environ. Hlth. Perspectives 10:103-108, 1975.

22. A. J. Alkezweeny and D. C. Powe 11, "Estimation of Transformation Rate of $\mathrm{SO}_{2}$ to $\mathrm{SO}_{4}$ from Atmospheric Concentration Data," Atm. Env. 11: $179-182,1977$.

23. A. Levy, D. R. Drewes and J. M. Hales, "SO Oxidation in Plumes: A Review and Assessment of Relevant Mechanistic and Rate Studies. Environmenta1 Protection Agency Document EPA-450/3-76-022, U.S. Office of Air and Waste Management, Office of Air Quality Planning and Standards, Research Triangle Park, NC, 1976.

24. G. E. Likens, "Acid Precipitation," Chem. and Eng. News, pp. 29-44, November 22, 1976. 
25. U.S. Environmental Protection Agency, 1973 National Emissions Report. Publication No. EPA-450/2-75-007, 1976.

26. U.S. Federal Power Commission, Steam Electric Plant Air and Water Quality Control Data, 1973. Publication No. FPC-S-253, 1976.

27. G. M. Hidy, C. Y. Tong, P. K. Mueller, Design of the Sulfate Regional Experiment (SURE). Publication No. EC-125, Electric Power Research Institute, 1976.

28. A. Eliassen and J. Saltbones, "Decay and Transformation Rates of $\mathrm{SO}_{2}$ as Estimated from Emission Data, Trajectories, and Measured Air Concentrations," Atm. Env. 9:425-429, 1975. 


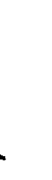




\section{DISTRIBUTION}

No. of

Copies

OFFSITE

A. A. Churm

DOE Patent Division

9800 S. Cass Avenue

Argonne, IL 60439

D. S. Ballantine

Department of Energy

Office of Biomedical and

Environmental Research Washington, DC 20545

R. W. Beadle

Department of Energy

Office of Biomedical and

Environmental Research

Washington, DC 20545

27 DOE Technical Information

Center

D. Dockery

Department of Environmenta 1 Health Sciences

School of Public Health

Harvard University

Boston, MA 02115

M. MacCraken

Lawrence Livermore Laboratory

University of California

P. 0. Box 808

Livermore, CA 94550

Paul Michael

Meteorology Group

Brookhaven Nationa 1 Laboratory

Upton, NY 11975

B. B. Hicks

Atmospheric Physics Section

Argonne National Laboratory

9700 S. Cass Avenue

Argonne, IL 60439
No. of

Copies
S. Hartwig

Battelle-Institute e.V

Am Romerhof 35

6000 Frankfurt am Ma in 90

GERMANY

J. L. Heffter

Air Resources Laboratory

National Oceanic and Atmospheric Administration

806013 th Street

Silver Spring, MD 20910

Dr. E. C. Voldner, ARQL

Atmospheric Environment Service 4905 Dufferin Street

Downsview, Ontario M3H 5TH

Dr. A. Venkatram

Ministry of the Environment

880 Bay Street

Toronto, Ontario M5S $1 Z 8$

Dr. C. M. Shieh, APS/RER, D-181

Argonne National Laboratory

9706 S. Cass Avenue

Argonne, IL 60439

Ron Meyers

Brookhaven National Laboratory

Upton, NY 11975

ONSITE

DOE Richland Operations Office

H. E. Ransom

26 Pacific Northwest Laboratory

R.L. Drake

D.C. Powe 11

L.L. Wende 11 
PNL-2734

UC-11

No. of

Copies

D.J. McNaughton (11)

W.J. Eadie

W.F. Sandusky

W.E. Davis

Technical Information (5)

Publishing Coordination (2)

G. B. Long (2) 